Jefferson Carú Guedes ${ }^{1}$ Rafael Figueiredo Fungêncio ${ }^{2}$ Larissa Moreno ${ }^{3}$ Fernanda Tercetti ${ }^{4}$

\section{Uma experiência do ensino participativo (e pesquisa): a redação de um artigo com alunos do mestrado e da graduação do UniCEUB*}

\author{
An experience of participative teaching \\ (and research): an essay on an article \\ written by Masters graduate students and \\ undergraduate students of UniCEUB
}

\begin{abstract}
"Uma vez mais repito categoricamente: não forneço qualquer regra capaz de transformar um homem em um poeta e de o levar a escrever versos. Essas regras não existem. Poeta é justamente o homem que cria as regras poéticas. (Wladimir Maiakóvski, Poética: como fazer versos)
\end{abstract}

\section{Resumo}

Descreve a experiência na redação de um artigo com a colaboração entre um professor e alunos de níveis diferentes de formação acadêmica, como parte da política de identificação de métodos de ensino e pesquisa participativa e seus desafios na sensibilização recíproca.

Palavras-chave: Ensino participativo. Pesquisa participativa. Metodologia. Redação jurídica. Artigo jurídico.

\begin{abstract}
This is a description of the experience of writing an article under the cooperation of a professor and students of different academic levels as part of the policy of identifying teaching methods and participative research and their challenges in achieving reciprocal attention.
\end{abstract}

Keywords: Participative Teaching. Participative Research. Methodology. Law Legal Essay. Legal Article.
* Artigo recebido em maio de 2013.

Aceito para publicação em junho de 2013.

1 Professor da Graduação, Mestrado e Doutorado do UniCEUB (Brasília)Doutor e Mestre em Direito Processual Civil (PUC-SP). Advogado da União.

2 Aluno do Curso de Mestrado em Direito e Políticas Públicas do UniCEUB (Brasília). Advogado da União.

3 Aluna do Curso de Direito do UniCEUB (Brasília).Aluna do Curso de Antropologia da UnB (Brasília).

4 Aluna do Curso de Direito do UniCEUB (Brasília)

5 Graduada em Contabilidade pela UnB (Brasília) Analista Técnica-Administrativa do MDIC 


\section{Introdução}

Este deve ser o relato de uma experiência na redação de um artigo com a colaboração entre alunos de níveis diferentes de formação acadêmica, incluídos graduação e pós-graduação stricto sensu, e um professor, como parte da política de identificação de métodos de ensino participativo e seus desafios na sensibilização entre professores e alunos. Neste caso, se trata propriamente de pesquisa participativa, pois envolve a busca de informações sobre grupos sociais e a redação de um artigo.

A ideia do texto coletivo, que aqui só vai indicado pelo título, ${ }^{5}$ surgiu também como fruto da colaboração e da participação de alunos, em uma aula do ProDI (Projeto Direito Integral) no UniCEUB (Centro Universitário de Brasília), no primeiro semestre de 2013.

Nessa oportunidade, com os alunos de graduação desse projeto de extensão acadêmica, que utiliza o método socrático, e em companhia das professoras Luciana Barbosa Musse, Christine Oliveira Peter da Silva e Betina Gunther Silva, discutíamos um texto do professor argentino Roberto Gargarella, ${ }^{6}$ e nos debatíamos com as inúmeras formas de ver e classificar os indivíduos e os grupos sociais considerados desiguais ou em desvantagem. A falta de um ou mais critérios para isolar e ordenar essas pessoas e esses grupos desiguais, identificada por alguns dos alunos participantes, foi o desafio lançado. Tínhamos que tentar vencê-lo, propondo alguns agrupamentos e algumas 'classes', uma provável classificação.

Saí da sala de aula do ProDI sabendo que havia algo mais a ser cumprido.

\footnotetext{
5 Sujeitos e Grupos Desiguais: uma tentativa inicial de listagem e de classificação segundo as leis e as políticas públicas brasileiras.

6 GARGARELLA, Roberto. Introducción, derecho y grupos desavantajados. Barcelona: YLS-UP- Gedisa, 1999.
}

\section{Os primeiros passos solitários e a crise}

Tão logo $\mathrm{me} \mathrm{vi}^{7}$ fora dessa sala, identifiquei a necessidade de classificação dessas categorias, ${ }^{8}$ tarefa que comecei a executar no mesmo dia, em uma pequena ficha pautada, onde se encontra o primeiro esboço de unificação e caracterização desses grupos sociais heterogêneos.

Disso, ainda nas anotações pessoais, individualmente, passei à redação de um sumário provisório, método para os primeiros passos que tem me acompanhado há muito e que sugiro a todos que possuem a natural dificuldade da partida, ou seja, de arrancar do 'nada' para chegar a um texto intermediário ou mesmo final. ${ }^{9}$

Tinha já em mente, nesse momento, o que poderia ser provavelmente o resultado, uma listagem de grupos sociais em desvantagem, que são alvo de políticas públicas compensatórias e que não estão até hoje 'classificados' pelo Estado, pelos pesquisadores, dificultando o ensino e o estudo. Havia ali, por certo, uma boa razão para prosseguir.

Mas como fazer isso diante de outras tarefas cotidianas já em andamento?

Confessei essa dificuldade à professora Luciana Barbosa Musse, responsável pelo NEAC (Núcleo de Extensão e Atividades Complementares) do UniCEUB, que prontamente me sugeriu: "estenda o convite aos alunos do ProDI", já que foi no contexto do projeto que surgiu a proposta. "Se eles aceitarem, faz a redação em conjunto e apresenta como experiência de ensino participativo em evento institucional deste ano."

7 O uso da primeira pessoa do singular em parte do texto indica a expressão do professor e suas opiniões, enquanto as dos demais participantes vão indicadas por notas de rodapé.

8 O estudo de grupos em desvantagem social, grupos desiguais, técnicas compensatórias de direito e de processo já era objeto de trabalhos anteriores que tenho produzido individualmente ou coletivamente. São exemplos: ROCHA, Eliana Pires; GUEDES, Jefferson Carús. Derechos Fundamentales y Proceso Civil en el Brasil: algunas técnicas procesales compensatorias de desigualdades sociales y la protección judicial de los derechos fundamentales. Anuario de Derechos Humanos, Madrid, Universidad Complutense de Madrid, v. 11, 2010. GUEDES, Jefferson Carús. Direito processual social no Brasil: as primeiras linhas. Revista de Processo, São Paulo, n. 142, 2006.

9 Parte dessa experiência está relatada no texto Pesquisa em direito e a produção de textos de curta extensão, publicado em obra pequena que reúne este trabalho e outro do professor uruguaio Américo Plá Rodriguez, com o título Como se escreve um livro jurídico: conselhos a um jovem que vai escrever um livro. 
Surgia assim uma nova proposta de risco e produção participativa, sob a qual há ainda poucos relatos conhecimos. ${ }^{10}$

Se der certo, pensei, teremos dois artigos: um sobre a classificação dos grupos em desvantagem social e outro sobre a experiência do ensino e pesquisa participativa. Se der errado o artigo sobre os grupos, pelo menos teremos um, sobre a experiência frustrada de redação do primeiro.

Portanto, o que se pretende neste meta-artigo (artigo sobre a redação do outro artigo) é apenas relatar a sucessão de acontecimentos, sem impor regras ou dizer quais são as melhores técnicas. Bem ao modo de René Descartes, ${ }^{11}$ mas sem o recurso retórico que se atribui a esse filósofo, vamos dizer por onde andaram ou vão andar os nossos próprios passos e, não, por onde deve ou devem andar os passos de quem se propõe a essas aventuras coletivas.

\section{O convite aos alunos, as condições e a adesão limitada: pesquisa participativa e colaboração}

Fiz o convite, então, aos alunos da turma especial da graduação, por meio da coordenação do ProDI, e aos alunos da disciplina de Controle processual de políticas públicas, do mestrado do UniCEUB, recebendo, de alguns, sinais de pronta aceitação, e de outros um obsequioso silêncio. Para quem deseja a colaboração e participação, basta isso. Alguns bons interessados; uns poucos que ve-

${ }^{10}$ Uma das raras e recentes obras sobre o tema é Ensino jurídico participativo: construção de programas, experiências didáticas, organizada por José Garcez Ghirardi e Rafael Domingos Faiardo Vanzella, com relatos de inúmeras experiências de construção de programas e de experiências didáticas na GV Direito, de São Paulo.

${ }^{11}$ No Discurso do Método, René Descartes alerta que seu: "o propósito não é ensinar (...) o método que cada um deve seguir para bem conduzir sua razão, mas somente mostrar de que modo procurei conduzir a minha. Aqueles que se metem a dar preceitos devem achar-se mais hábeis do que aqueles a quem os dão; e, se falham na menor coisa, são por isso censuráveis. Mas, propondo este escrito apenas como uma história, ou, se preferirdes, apenas como uma fábula, na qual, dentre alguns exemplos que podem ser imitados, talvez também se encontrem vários outros que se terá razão em não seguir, espero que ele seja útil a alguns sem ser nocivo a aninguém, e que todos apreciem minha franqueza." DESCARTES, René. Discurso do Método. 2. ed. São Paulo: Martins fontes, 1999. Parte 1, p. 7-8. jam nesse desafio a oportunidade de produzir coletivamente com todas as suas desvantagens e vantagens.

Dentre as vantagens, para o aluno estreante, estão: ver-se publicado e sair do ineditismo; manifestar suas próprias ideias, por escrito; treinar-se em grupo para, depois, aceitar desafios individuais; exercitar as atividades mais comuns no pesquisador, quais sejam, refletir, discutir, sistematizar e sintetizar ideias, escrever, entre outras.

Dentre as possíveis desvantagens estão: $\mathrm{o}$ acúmulo de tarefas e atividades em períodos críticos de estudos, de provas e verificações, de apresentações de seminários ou de outras tarefas escolares.

As vantagens apontadas pelos alunos participantes são diversas, mas assemelhadas.

Para Rafael Figueiredo Fulgêncio, são vantagens a "possibilidade de publicar um artigo com um professor reconhecido e de aprender a forma como este autor experiente escreve e coordena o projeto", a produção de um "escrito comum [que] se aproveita, também, das experiências e das visões de cada um de seus autores," mas, ainda , "a divisão do trabalho [que] talvez seja a única possibilidade de [...] estar envolvido na feitura de um artigo durante o semestre letivo, tendo em vista [...] [a] reduzida disponibilidade de tempo."12

Fernanda Tercetti vê como vantagens a "oportunidade de expor ideias e vê-las circulando na academia, o que contribui em muito para o empoderamento do aluno" por ver-se "capaz de trabalhar suas ideias e impressões sobre a teoria e a realidade ao ponto de serem aceitas para uma publicação" e capaz de tornar o trabalho mais rico. Pois, "cada pessoa possui um arcabouço único de ideias, impressões, entendimentos sobre a realidade etc., o que certamente contribui para o conjunto trabalho em razão da multiplicidade de visões e abordagens dos temas que pode resultar."13

Para Larissa Moreno, são vantagens "da produção coletiva $[. .$.$] o seu próprio ineditismo e autenticidade.$

${ }^{12}$ Opinião de Rafael Figueiredo Fulgêncio, aluno do Mestrado em Políticas Públicas, coautor deste meta-artigo, respondendo a questão sobre as vantagens de redação do artigo e pesquisa participativos.

${ }^{13}$ Opinião de Fernanda Tercetti, aluna de Graduação em Direito, coautora deste meta-artigo, respondendo à mesma questão sobre as vantagens de redação do artigo e pesquisa participativos. 
Isso porque surge como desafio ao modelo de produção existente, sendo assim, audaz. Outra vantagem é o fato de abrir a possibilidade para os participantes partilharem de visões e opiniões distintas, o que contribui para o enriquecimento da produção. Ademais, otimiza o tempo de produção, dado que ela será realizada por mais de uma pessoa, permitindo que abranja maiores detalhes e, é claro, a interdisciplinaridade. Ainda, ter uma pessoa figurando como coordenadora da produção é de suma importância para consolidar as ideias, bem como orientar os demais participantes." ${ }^{14}$

A colaboração pode ser a única forma possível de produção em um cenário de múltiplas atividades hoje vivenciada pelos estudantes e professores, quando se somam as tarefas acadêmicas e os deveres a elas associados; mas, para além disso, mostra-se como um prazeroso exercício e uma constante aprendizagem para todos os participantes. Ainda que as descobertas, os inventos ou as idéias inovadoras possam ser produções individuais ou mesmo solitárias, o enfrentamento e debate são capazes de produzir resultados surpreendentemente mais ricos.

P. B Medawar, nos seus conselhos a um jovem cientista, diz que sinergia é a palavra chave nos processos acadêmicos de colaboração, pois:

[...] indica que o esforço conjunto é maior que a soma das diversas contribuições -, mas a colaboração não é obrigatória, ainda que muitos pronunciamentos se possam fazer relativamente à superioridade da equipe sobre o indivíduo. A colaboração é um sucesso quando funciona bem, mas muitos pesquisadores podem desempenhar-se muito bem trabalhando sozinhos. ${ }^{15}$

E, por não ser obrigatória, é que a produção colaborativa ou participativa pode ser atrativa. Deve haver no convite e na exposição das vantagens a demonstração das virtudes do trabalho em equipe, pois se sabe que ele poderia ser desenvolvido individualmente.

${ }^{14}$ Opinião de Larissa Moreno, aluna de Graduação em Direito, coautora deste meta-artigo, respondendo à mesma questão sobre as vantagens de redação do artigo e pesquisa participativos.

${ }^{15}$ MEDAWAR, P. B. Consejos a un joven cientifico. México: FCE, 1979. Item 5, p. 56. Este trabalho escrito há mais de 60 anos traz ricas e atuais experiências de um pesquisador da área da medicina na Inglaterra.

\section{As dificuldades da redação coletiva de textos}

Escrever é uma missão difícil.

Escrever em grupo é ainda mais, pois se somam as questões organizacionais e de coordenação como aquelas decorrentes da polifonia, da multiplicidade de entonações e de falantes. Bem adverte Paul Valéry que, "se várias pessoas falarem ao mesmo tempo, só se pode acompanhar o discurso de uma delas." ${ }^{16}$ No texto vale a mesma regra, se cada um escreve de um modo e não se unifica formalmente esse discurso, mais trabalho terá o leitor para unir essas diferenças textuais ${ }^{17} \mathrm{e}$, depois, ainda, compreender a mensagem de fundo.

Para tanto é preciso organização, ou seja, uma clara definição de atribuições individuais, a definição de um meio de comunicação objetivo e capaz de informar o estado evolutivo de cada parte, uma certa uniformidade de linguagem, tolerância, capacidade de ouvir e incorporar opiniões discordantes das nossas, mas, antes de tudo, coordenação.

O papel do coordenador, que neste caso compete ao líder da pesquisa ou do trabalho, não deve constranger ninguém; nem ao líder, nem aos liderados. Essa coordenação é necessária para que se tenham certas metas e sejam atendidos os prazos, orientações objetivas e a verificação inicial sobre a coesão e a coerência textuais, às vezes ausente mesmo em textos monoautorais.

Mas a vigilância quanto à coesão $0^{18} \mathrm{e}$ à coerência ${ }^{19} \mathrm{e}$ papel de todos, embora dependa da precisa definição do tema geral e dos temas individuais, não havendo diferenças nessa dificuldade quando a participação no texto coletivo é de professores ou de alunos e professores.

${ }^{16}$ VALÉRY, Paul. Introdução ao método de Leonardo da Vinci. São Paulo: Editora 34, 1998. p. 41.

${ }^{17}$ Outra coisa é a diversidade de opiniões e a riqueza que dela advém. São benvindos os desacordos e conflitos intelectuais que possam, pela riqueza da contradição, trazer mais informações, novas abordagens, novas reflexões.

${ }^{18}$ A coesão está relacionada com o uso adequado dos elementos de ligação - chamados conectivos - que possibilitam a ligação de ideias e mantém o nível adequado de harmonia entre as ideias relacionadas; decorre da unidade formal do texto, obtida por meio de mecanismos gramaticais e lexicais.

${ }^{19}$ A coerência é a maior responsável pela formação de sentido do texto, envolve aspectos lógicos, semânticos, cognitivos e depende de uma lógica ordenada de conceitos e relações estabelecidas na construção do artigo; está relacionado também com o nível de interpretabilidade por parte do leitor, inteligibilidade e sequencialidade ordenada de ideias. 
Sobre as principais dificuldades, observa Rafael Figueiredo Fulgêncio que "não diz respeito à produção coletiva, mas à compatibilização da feitura do artigo com as atividades profissionais e das três disciplinas do mestrado que estou cursando", mas "outros problemas podem aparecer na hora da redação do texto final do artigo que, além de trabalhosa, envolverá a supressão ou modificação de partes do texto escrito por cada um dos colaboradores." ${ }^{20}$

Dentre as dificuldades da produção coletiva, observa Fernanda Tercetti que "a incompatibilidade dos horários dos participantes e os problemas na concatenação da produção de cada um para formar o todo. Quanto àquela, reconheço que pode ser minimizada pelo uso de comunicação eletrônica, que, porém, jamais suprirá o calor e a intensidade de troca de informações e experiências que os encontros 'ao vivo' podem trazer. Gestos, entonações, olhares, expressões faciais, etc são itens da comunicação que podem exprimir mais sentido do que as palavras. Tive essa percepção de modo mais objetivo esses dias, quando estava conversando com um amigo. Na ocasião, sempre que eu tentava explicar meu ponto de vista, sentia que as palavras que vinham à minha mente não se adequavam muito ao que eu queria dizer, então eu acabava me utilizando de gestos e ele compreendia de pronto o que eu estava querendo dizer. No tocante ao desafio de concatenação das produções para compor o todo, recordo-me dos trabalhos em grupo durante a minha primeira graduação, na UnB, em Ciências Contábeis. Em decorrência da incompatibilidade de horários de cada um, nos restava, apenas, a opção de produzir à distância’, em separado, para, depois juntar tudo e compor o todo. Essa tarefa era sempre dificultosa, pois o assunto que o grupo deveria desenvolver era contínuo e, de certa forma, sucessivo. Para consolidar o trabalho, as partes de cada um precisavam ser revistas e quase sempre era necessário consultar o autor para compreender o sentido de algumas das suas ideias para, então, concatená-las com a parte que seguiria." ${ }^{21}$

Como dificuldade à produção coletiva, Larissa Moreno indica "diferença de nível de conhecimento entre os participantes em relação ao objeto da pesquisa. Em razão da idade, nível social, ambientes de convívio ou experiências por que passaram na vida, que obviamente diferem de pessoa para pessoa, cada participante terá diferentes níveis de compreensão sobre o objeto da pesquisa. Assim, as partes produzidas por cada apresentará diferentes níveis de profundidade de abordagem do tema. Por outro lado, entendo também que essa dificuldade pode ser encarada como um ponto favorável à produção coletiva, sendo a produção elaborada de forma interdisciplinar, na medida em que cada participante irá tratar do tema utilizando-se dos conhecimentos que detém, que são variados. ${ }^{22}$

Todos são relatos muito vivos das dificuldades de um e de outro que demonstram situações concretas de alunos que mantém dupla jornada de trabalho e estudo, realidade comum nos cursos de graduação e pós-graduação em Direito.

\subsection{Os desníveis de participação e a média desejada}

Qualquer atividade que envolva um conjunto de pessoas pode despertar comparações sobre o quanto cada um contribui para o todo. Essa avaliação pode ser boa ou não, principalmente se permite a identificação de falhas e sua correção.

O que se pode avaliar não é a existência de uma divisão equânime do trabalho, mas o atendimento das tarefas que cada participante está comprometido. A divisão pode, sem nenhum problema, privilegiar habilidades de um ou outro participante, sem que todos participem de todas as etapas ou encargos. Mas a riqueza da experiência advém, por certo, da participação no máximo, das etapas ou momentos de pesquisa e redação.

Não se pode exigir idêntica colaboração de todos os participantes, pois isso produz mal estar e traz baixos resultados, sem considerar as diferenças pessoais, as capacidades, assim como as limitações de cada um. Desde que sejam definidas e acordadas, as tarefas podem ser desigualmente distribuídas entre os participantes.

Desníveis, assim, são inevitáveis e naturais.

\subsection{Os desaparecimentos e os aparecimentos}

Nas jornadas longas, o caminho vai definindo como se anda e, também, o comportamento dos participantes da caminhada. Alguns se adiantam, outros mantêm o ritmo e permanecem coesos ao grupo, alguns se atrasam e outros desaparecem.

\footnotetext{
${ }^{20}$ Opinião de Rafael Figueiredo Fulgêncio.

${ }^{21}$ Opinião de Fernanda Tercetti.
}

${ }^{22}$ Opinião de Larissa Moreno. 
Nenhum desses comportamentos deve causar uma surpresa absoluta, pois eles decorrem de diferenças pessoais, de compromissos paralelos, de problemas individuais e de outras questões. Ideal é que certo grupo ou núcleo comece e termine o trabalho, mas haverá no curso do trabalho alguns 'desaparecimentos' lamentáveis e bons 'aparecimentos'. Novos integrantes trarão mais disposição e novo fôlego ao trabalho. Os novos serão saudados com efusão, os que saem serão, em geral, lamentados.

As 'portas' podem estar abertas em qualquer etapa do trabalho, mesmo nas finais.

\subsection{Um método mágico ou o relato de algumas técnicas facilitadoras? A comunicação}

Como lembrado anteriormente por René Descartes, nas páginas iniciais do Discurso do Método, que ele não viera dizer como cada um deve se portar, mas apenas informar como ele se portara.

Não há métodos adequados ou inadequados para uma ou outra pessoa, mas pessoas ou grupos que se afinizam a certo modo de trabalhar, a certa técnica. Essa identificação só pode surgir da própria experiência e possivelmente não se possa aqui declarar o sucesso desse modo de produção, mas talvez a partir da segunda ou terceira experiência similar.

Uma das formas encontradas para o 'preenchimento' de cada grupo social identificado foi a formulação de duas ou três perguntas que, respondidas, permitiriam o desenvolvimento de cada item correspondente a esse grupo de pessoas pesquisadas.

As perguntas apresentadas aos participantes foram: $:^{23}$

a) como são definidas pela lei tais pessoas? ${ }^{24}$

b) possuem tais pessoas vantagens compensatórias dadas pela lei?

${ }^{23}$ Essas perguntas devem ser respondidas para cada um dos subitens, para cada um dos grupos em desvantagem. As perguntas foram encaminhadas por meio eletrônico aos participantes.

${ }^{24}$ Exemplo: considera-se negro a aquele que se autodeclara preto, pardo ou denominação análoga, no quesito cor e raça das pesquisas do IBGE (Estatuto da Igualdade Racial, Lei n. $12.288 / 2010$, art. $1^{\circ}$, par. ún., inc. IV). c) quais são essas vantagens legais desse grupo? ${ }^{25}$

A busca dessas informações é, precisamente, a atividade de pesquisa e o 'preenchimento' já é a redação do texto do artigo, pela identificação desses grupos sociais no emaranhado legal, identificação de direitos e bens oferecidos pela política pública. Diante dessas observações pode-se dizer que essa pesquisa se ajusta ao tipo denominado jurídico-exploratório, pois se desenvolve como uma "abordagem preliminar de um problema jurídico; (...) ressalta características, percepções e descrições sem se preocupar com suas raízes explicativas; (...) abre caminho a investigações maisprofundas ou a hipóteses mais precisas." 26

Mas a compreensão mais exata do projeto pode ser obtida a partir de uma vista sobre o Sumário proposto, pois essa estrutura permitiu a divisão do trabalho, de pesquisa e de redação.

A tarefa do coordenador, após isso, é receber e ordenar os trechos parciais que 'preenchem' as lacunas. Segundo os participantes: "a comunicação, que poderia ser um problema, parece facilitada pelo uso do e-mail" ou pelo convívio direto, quando isso é possível. ${ }^{27}$

\subsection{Nosso sumário provisório}

Antes de apontar o sumário, deve-se recordar o título do artigo: Sujeitos e Grupos Desiguais: uma tentativa inicial de listagem e de classificação segundo as leis e as políticas públicas brasileiras, assim como a finalidade, que pode ser sintetizada na busca de diferenciações legais, criadas para compensar tais grupos, considerados em desvantagem ou socialmente vulneráveis.

Abaixo vai indicado, apenas para a satisfação de alguma curiosidade, o Sumário do artigo:

${ }^{25}$ Exemplo: os indígenas, pela Lei n. 12.711/2012 - que dispõe sobre o ingresso nas universidades federais e nas instituições federais de ensino técnico de nível médio - têm reservadas para si vagas escolares, na proporção de sua participação na população da unidade federativa (art. $\left.3^{\circ}\right)$.

${ }^{26}$ GUSTIN, Miracy; Barbosa de Souza; DIAS, Maria tereza Fonseca. (Re)pensando a pesquisa jurídica: teoria e prática. Belo Horizonte: Del Rey, 2002. p. 49.

${ }^{27}$ Até o momento de finalização do artigo foi feita apenas uma rápida reuniãopresencial entre os quatro participantes, sendo a comunicação feita quase que exclusivamente por mensagens eletrônicas. 


\section{SUMÁRIO:}

1 Introdução;

20 que são afinal desigualdades?;

3 Em que se pode ser desigual? E quanto?

4 As desigualdades e suas múltiplas denominações;

5 Critérios classificatórios de sujeitos e grupos desiguais beneficiados por políticas compensatórias;

5.1 Critério segundo a renda;

5.2 Critério segundo o gênero;

5.3 Critério segundo a etnia ou raça;

5.4 Critério segundo a profissão, emprego ou trabalho;

5.5 Critério segundo a faixa etária;

5.6 Critério segundo o gozo ou não de saúde;

5.7 Critério segundo a posição econômica ou uso de bens e serviços;

5.8 Critério segundo a relação com a Seguridade Social;

5.9 Critério segundo a limitação no exercício de Direito Público;

5.10 Critério segundo a limitação no exercício de direitos a não-brasileiros;

6. Conclusões

Quando este Sumário foi enviado pelo professor aos demais participantes, já possuía a estrutura atual e quase todos os itens que estão agora listados. Os subitens, onde estão indicados individualmente os grupos de pessoas em desvantagem, estavam precariamente arrolados. Logo, somente serão completamente definidos no curso da pesquisa e da concreta identificação enquanto grupos sociais nessa condição. Como se busca identificar vantagens compensatória legais, é precisamente a busca dessas leis especiais que permitirá incluir ou não certo grupo social em uma dessas categorias. Negros, por exemplo, é (são) grupo que recebe compensações por cotas em universidades e escolas técnicas federais, justificando sua inclusão no item n. "5.3", relativo ao "Critério segundo a etnia ou raça", assim como Idosos, situado no grupo isolado pelo "Critério segundo a faixa etária", que possui também outras vantagens compensatórias materiais como passes em transporte coletivos ou a tramitação preferencial em processos judiciais.

Um exemplo de subdivisão já pesquisado é do item n. "5.10, pelo "Critério segundo a limitação no exercício de direitos a não-brasileiros", para o qual se identificou na lei os conceitos e os direitos atribuídos a imigrantes, refugiados e apátridas.
5.10 Critério segundo a limitação no exercício de direitos a não-brasileiros

5.10.1 Imigrantes

5.10.2 Refugiados

5.10.3 Apátridas

Somente a pesquisa e a concreta identificação desses direitos é que justificarão a inclusão em uma dessas categorias, trabalho esse que compete precisamente ao pesquisador encarregado daquele "Critério" classificatório.

\section{0 estágio atual do trabalho sobre grupos em desvantagem social}

$\mathrm{Na}$ fase inicial foi proposto e, de modo geral aceito pelos interessados, que assumissem sozinhos algum dos 'grupos segundo certo critério'. Esta divisão entre os participantes só pode ser assim feita em trabalhos como este ou com estrutura similar, nos quais a própria subdivisão permite a independência (relativa) e o desenvolvimento em separado.

Até aqui houve a distribuição de grupos/tópicos para os participantes, cabendo a cada um de nós, ao seu modo e com certa independência, buscar em bases legais, na legislação, a identificação conceitual desses grupos e seus direitos diferenciados e ou compensatórios.

Não há neste momento, ainda, a certificação de que a pesquisa produzirá o que se espera, embora intuitivamente se saiba da existência de diversos direitos destinados a diversos grupos sociais especiais. Mais que isso, em alguns grupos, não apenas intuitivamente, são conhecidos os direitos sociais a eles atribuídos, como nos casos de idosos, crianças e adolescentes, mulheres etc.

Serão estabelecidos prazos de 30 (trinta) dias para a entrega das contribuições individuais, uma essencial reunião geral de revisão e certo prazo final (talvez de 30 dias também) para a conclusão e revisões.

\section{Conclusão}

O que se pode avaliar até este momento, como lições recolhidas da experiência de produção coletiva, envolvendo professor e alunos de níveis acadêmicos diversos, é plena possibilidade de sucesso com a redação do texto almejado quando estão claros os objetivos e as 
tarefas. Essa objetivação e clareza se expressa no planejamento do trabalho e na metódica e coordenada execução.

Ter-seá como objetivo o desenvolvimento de competências relacionadas à busca e registro de informações (pesquisa) e de aprofundamento e redação do texto final (relatório) que deve ser apresentado sobre a forma de um artigo. Em sí, esse produto já é suficiente a revelar a experinetação do processo coletivo e participativo de produção.

\section{Referências}

DESCARTES, René. Discurso do Método. 2. ed. São Paulo: Martins fontes, 1999.

GARGARELLA, Roberto. Introducción, derecho y grupos desavantajados. Barcelona: YLS-UP- Gedisa, 1999.

GHIRARDI, José Garcez; VANZELLA, Rafael Domingos Faiardo. Ensino jurídico participativo: construção de programas, experiências didáticas. São Paulo: Saraiva, 2009.

GUEDES, Jefferson Carús. Direito Processual Social no Brasil: as primeiras linhas. Revista de Processo, São Paulo, n. $142,2006$.
GUSTIN, Miracy Barbosa de Souza; DIAS, Maria tereza Fonseca. (Re)pensando a pesquisa jurídica: teoria e prática. Belo Horizonte: Del Rey, 2002.

MEDAWAR, P. B. Consejos a un joven cientifico. México: FCE, 1979.

NOBRE, Marcos et al. O que é pesquisa em Direito? São Paulo: Quartier Latin, 2005.

PLÁ RODRIGUEZ, Américo; GUEDES, Jefferson Carús. Como se escreve um livro jurídico: conselhos a um jovem que vai escrever um livro. Pesquisa em direito e a produção de textos de curta extensão. Campinas: EdiCAMP, 2003.

ROCHA, Eliana Pires; GUEDES, Jefferson Carús. Derechos Fundamentales y Proceso Civil en el Brasil: algunas técnicas procesales compensatorias de desigualdades sociales y la protección judicial de los derechos fundamentales. Anuario de Derechos Humanos, Madrid, Universidad Complutense de Madrid, v. 1, 2010.

VALÉRY, Paul. Introdução ao método de Leonardo da Vinci. São Paulo: Editora 34, 1998. 